Intro

\title{
The Changes that COVID-19 Catalysed for Audiovisual Industries
}

$\$$ sciendo

INDREK IBRUS, Tallinn University, Estonia; email: ibrus@tlu.ee

TEET TEINEMAA, Tallinn University, Estonia; email: teinemaa@tlu.ee 
Earlier this year - during what in retrospect was the tail end of the first wave of the COVID-19 pandemic - Baltic Screen Media Review (BSMR) put out a call for papers asking scholars to reflect on how these unprecedented times might change audiovisual cultures, perhaps permanently. The challenge that the pandemic had caused for the field could not have been more evident. The cultural sector (along with travel and leisure industry) was the first and hardest-hit by restrictions aimed at curbing the spread of the virus. We saw cinemas, theatres, and galleries close and restrictions on movement that rendered film shooting, location scouting and casting impossible. The situation was no less of a challenge for broadcasting, with the responsibility for public broadcasting more than ever in the spotlight to deliver accurate information, while populist forces were aiming to take advantage of the chaotic situation in the interest of propagating their message. Anna Jupowicz-Ginalska (2020) examines a similar concern within this current issue in her article on Polish magazine covers.

At the same time, as mobility was limited and the gathering of live audiences forbidden, many talk show hosts had to resort to filming from home. This often meant talking into a static camera on a tripod and turning their family into crewmembers. Practically overnight, famous TV hosts became podcasters and streamers and some of the biggest names in show business, such as Ellen DeGeneres and Conan O'Brien, were either contemplating an end to their career or transitioning to a new platform online. With the more traditional exhibition venues closed, it was blatantly clear how this could positively affect transnational streaming giants and lead to an even greater consolidation in this area. Meanwhile at BSMR we were asking - Could the pandemic also function as a catalyst for change in the audiovisual field by potentially creating momentum for innovation and favouring more flexible smaller players?

We are glad to announce that the call for papers was very well-received and that these and many other areas of interest are well-covered in this issue of BSMR with a special focus on "Pandemic as a Catalyst for Change in Audiovisual Cultures." While, at the time of writing, the second wave of the pandemic reigns and there are clear signs of fatigue regarding the topic, we hoped that the shorter think-piece nature of the essays and the open-access format of BSMR would provide us with an apt opportunity to academically respond to the crisis and explore the potential benefits that could emerge from this situation for the audiovisual cultures.

As we were reading the contributions, we were intrigued to learn that great change has occurred in all parts of audiovisual industries' value chains and many of these changes appear to be long term, or at least to suggest various new directions in the development of these industries. In some areas, the pandemic made crises and challenges that may have been brewing underneath the surface more clearly visible and the need for change more immediate.

In our view, a primary tension that existed before (but clearly intensified during the crisis) was between concentration on global media markets and the need for autonomous and independent national media and cultural institutions. As Lothar Mikos (2020) highlights in the current volume, while people in lockdown began to stream significantly more online content, they predominantly used the big American platforms. Mikos demonstrates that, with the exception of Scandinavia, there are no platforms in Europe able to compete with the US-based corporate giants. Therefore, when it comes to streaming, the pandemic seemed to accelerate an ongoing global market concentration.

Yet the question remains: what kind of content and whose productions were viewed predominantly on these platforms? As Ulrike Rohn (2020) has shown, the pandemic paralleled with the intensification of the global 'streaming war' among the major platforms including Netflix, Amazon Prime Video, Disney+, Hulu, HBO, to name a few. This struggle for dominance also had the 
potential for benefitting producers in small countries, mainly because the 'war' caused the global platforms to focus more on localisation and this, in turn, resulted in the commissioning of works from producers in smaller countries. There has been news, for instance, of Danish creators of TV-series who were busy producing new content before the pandemic struck.

Nonetheless, as demonstrated by Marius Øfsti (2020) in this volume, benefits for the Norwegian filmmakers were far from clear. As cinemas were closed, many of the new films had, in essence, only one option left for exhibition and distribution: VOD platforms. Many filmmakers were willing to try out these options, only to learn that the Norwegian films that were released early on VOD faced very strong competition for attention with Hollywood titles. Additionally, the financial returns for instance, from Apple iTunes - were not significant and, despite the fact that a few Norwegian films were also purchased by SVOD services such as Netflix, there were no indications that VOD could become a viable alternative to cinema for most Norwegian movies. This is even more pronounced given that cinemas were gradually reopening in the summer and - despite the fact that the general cinema attendance was more than halved compared with the same time period in 2019 - Norwegian titles showed significant growth in terms of audience share. All existing records in terms of the share of Norwegian films in the overall viewership were broken. Altogether, $\varnothing$ fsti demonstrates that even a very limited cinematic exhibition seems to have been more beneficial for producers than a relatively high-profile VOD-release on global platforms. It appears that, in the first place, audiences find local films in cinemas and that this trend is a constant that will continue to shape both the market structures and value chains in small markets in the near future.

This associates closely with arguments made by Caitriona Noonan (2020) in this volume. Noonan argues, firstly, that film funds across the small countries (especially in the Northern Europe) have supported production companies by offering more flexible terms including extended deadlines, accelerated payment of grant funding or deferred loans and levies. Further, she emphasises that the role of film funds is to make sure the screen media sector is 'open for business' and part of this is a greater focus on distribution compared to the production of films. Limited attention to distribution has been generally viewed as a problem before (European Audiovisual Observatory, 2019a: 19), but COVID-19 has been catalysing focus on this. However Noonan also emphasises the risks of concentration in this area, arguing that film funds would need to make sure that the pandemic does not contribute to the further consolidation of big cinema chains and that independent cinema remains a visible and viable part of community life in Europe. This risk has been real due to the advantages of major cinema chains as they rely on the economics of scale that usually provide a more firm capitalisation, and most often benefit from better contractual relationships with bigger international distributors.

Mikos in this journal (2020), however, opens up another issue regarding the role of film funds and cinema exhibitions. Mikos argues that there has been an overproduction of art house films in Europe. He demonstrates that in 2017 alone, 2200 feature films and 731 documentaries were released in Europe (European Audiovisual Observatory, 2019b: 10) and argues that this number of films leads to a fragmentation of the offer as films in cinemas 'cannibalise' each other. "More and more European films have fewer and fewer viewers and are shown for shorter and shorter periods on the big screen," Mikos writes. We argue that the pandemic made this issue even more salient - as this summer and autumn (and also in the forthcoming winter and spring) cinema schedules have been out of sync and films have had short running periods in cinemas, which unavoidably affects the revenues of production studios and undermines their sustainability. Even 
more apparent is the struggle for attention, with premiers overlapping and piling together during the short summer timeframe between two waves of the virus. At least, this is what we have witnessed here in Estonia. Maybe the ongoing catalysation will force the film funds to think through future distribution strategies, audience demand, and how many and what kind of films are being financed and produced.

Returning to the topic of market concentration and platformisation, the article in this issue by Minna Horowitz and Ritva Leino (2020) is enlightening, reporting on the ways in which Finnish public service broadcaster Yle reacted to the pandemic. They write that Yle's audience numbers went up quickly, audience trust continued to be high, and private competitors recognised the high quality of their work. Such a high standard of accurate and unbiased reporting has unfortunately not been the case everywhere. This is demonstrated by Jupowicz-Ginalska's (2020) article, in which she discusses the politicisation of COVID-19 coverage by Polish socio-political magazines, concentrating specifically on how cover images further support media polarisation in Poland.

In the case of Finland and Yle, however, even among the younger audience, viewership numbers increased significantly and their trust was equally high. Yet, Horowitz and Leino write also that audiences' demands started to shift as the pandemic progressed. Instead of public service media (PSM), it was the social media that started to win the popularity contest for public communication. They argue that this was the case because the social networks enable interactivity and worldwide participation possibilities - something that PSMs cannot do or have not traditionally done. While some PSM organisations do offer their own streaming services, they do not host specific platforms for interactions.

Nevertheless, Yle demonstrated a swift and adequate reaction to the unprecedented health crisis. For instance, as the lockdown created demand for educational content the Finnish Broadcasting
Company (Yle) quickly added relevant children's content. In addition, when the audiences seemed to desire more entertainment during the perplexing times, Yle added more music programming. It became apparent, despite these positive initiatives, that universal reach can only be achieved by submitting to the commercial imperatives of social media networks and creating a PSM presence on TikTok and Twitter, among other platforms. Unexpectedly, Yle's social media activities that promoted an interactive, live presence and uplifting content were found to be the modality that met the needs for connection and togetherness. Horowitz and Leino write that the internal analysis within Yle concluded that merely adding volume to programming whether informational, educational or entertaining - was not enough. Audiences/ users expected services that positioned them as co-creators and not merely as passive spectators. The authors therefore suggest that spring 2020 was a 'test laboratory' for Yle and a significant opportunity to rethink and innovate in their approach. The primary learning outcome from spring 2020 has been that organisations with the agility to create new services according to audiences' needs, and with the commensurate ability to engage with these audiences, tend to be the winners in this situation of a 'new normal.' The crisis was a catalyst for a clear understanding that PSM organisations need to invest proactively in content and services that provide interaction and collaboration with and among audiences.

To an extent, but in a different way, this conclusion was also confirmed by Lothar Mikos in this volume. He points out that, in Germany as well, the pandemic supported the 'comeback' of linear television. Both the RTL group and the Public Service Broadcaster ARD launched new production initiatives for drama series that are first made available on online platforms. Developments are similar where we write, here in Estonia. The Public Service Media institution ERR launched its new VOD platform "Jupiter" during the pandemic. Timing was somewhat accidental as 
the work on the platform had been ongoing, and it is now claimed that "Jupiter" also works on new 'online first' content.

Yet, Mikos still points out the importance of international platforms for providing work for the audiovisual industries and encouraging innovation. Especially Amazon Prime Video and Netflix localise their content and commission related works from local producers. Can we say that this is the same in small countries?

Rohn (2020) has recently pointed out that in the context of the ongoing streaming war the mantra 'adapt or die' has often been referred to in the industry. The idea behind this motto is that, eventually, only those who can best serve the local audience will survive. This trend counters the situation before the pandemic, when Netflix tended to argue that, having identified the taste patterns and segments of cosmopolitan audiences, they did not need to make special efforts to serve the audiences in smaller countries any differently. During the pandemic, however, they introduced a recommendation system that tells Estonian audiences what most other Estonian audiences have watched. Through this change, platforms such as Netflix recognised the continuing relevance of the "cultural proximity' principle (Straubhaar, 1991) and that, although high-quality content tends to be well-received across national and cultural boundaries, there are still differences in cultural tastes across countries (see also Hartley et al., 2020).

In many bigger countries, such as Germany, Netflix has gone a step further by producing and commissioning local production. So far, this has not happened for Estonia. The question is whether Estonia might be too small and financially unrewarding for Netflix to invest in original production. Rohn (2020) proposes that this also depends on quality; on how good (and therefore competitive) local Estonian content is. The paradox is that the more local productions can meet the standards of international productions in quality and reputation, the more international players will invest in localising. Rohn suggests that the pandemic pointed more immediately to a need for investment in new TV formats and content production; a TV-specific policy focus that has thus far been missing in Estonia.

In this volume, Tim Raats (2020) points to the benefits of such an approach and demonstrates a case in which a pandemiccatalysed experiment in Flanders (another small area of Europe) relied upon decades of systematic policy effort to promote innovation and quality content production. The article describes the production of "Lockdown" an experimental anthology series developed by two production companies under strict COVID restrictions that centres on a prison visiting space. Raats argues that the need to produce under strict hygienic and social distancing rules resulted in a unique creative concept that, ironically, might not have been achievable under normal circumstances. His analysis shows that the smallness of the Flemish market, which over the past decades resulted in an industry dynamism characterized by improvisation, voluntarism, high dependency on collaboration, and short term financial planning, is what might have provided the backdrop for the production of this unique series.

Alexandre Zaezjev's (2020) article, also in this volume, similarly demonstrates pandemic-motivated creative solutions for the reception of Ilya Khrzhanovsky's grand cinematic project DAU (https://www. dau.com/en) - one of the largest and most unique film production projects of recent times. Because the more traditional exhibition venues such as film festivals and screenings in cinema were postponed for the foreseeable future, the project was moved online. Furthermore, the exceptional circumstances generated by the pandemic were integrated into the cinematic world of DAU. Through Michel Foucault's concept of heterotopias, or the alien 'mini-worlds' within our world, Zaezjev argues that it was, in many ways, because of pandemic limitations [the other to the prior state of social organisation] that the project was able to research its full potential. 
This issue of BSMR with a focus on COVID-19 as a catalyst for audiovisual industries has begun to unravel the effects that the virus has had - and continues to have - on audiovisual cultures. From a variety of different viewpoints this journal issue shows how the rapid spread of the virus left practically no corner of the audiovisual and print media untouched. The virus-related disturbances have affected projects from art house cinema sphere to the design of political magazines, and from the production of public media in some of the smallest regions of Europe to the drive for dominance of the international media conglomerates. With the second wave of virus underway as we write, and still seriously interrupting normal practices while deeply affecting the audiovisual cultures, the current issue does not propose to draw any lasting conclusions. Rather, the issue itself was also catalysed by the spread of the virus and the need to academically chart some of the ongoing changes.

The aim then - which we believe has been adequately fulfilled - was to begin thinking about and mapping out areas in which the pandemic has already acted as a catalyst, either by accelerating ongoing trends or changing practices outright that were shown to be too rigid in the new conditions. The pandemic has sped up and supported media consolidation and nationalistic tendencies, paradoxically favouring flexible small players while highlighting the demand for clear and accurate information and calling for innovation in the more traditional media enterprises. Likely only in retrospect will we fully understand some of the processes that the rapid global spread of the virus has catalysed. Yet, it is both an academic pleasure and responsibility to begin offering certainty on these conundrums before they truly unravel. We hope this issue serves as a step towards clearer times.

\section{REFERENCES}

European Audiovisual Observatory (2019a) Mapping of film and audiovisual public funding criteria in the EU. Strasbourg: European Audiovisual Observatory. European Audiovisual Observatory (2019b) Yearbook 2018/19. Key Trends. Strasbourg: European Audiovisual Observatory.

Hartley J, Ibrus I and Ojamaa M (2020) On the Digital Semiosphere: Culture, Media and Science for the Anthropocene. London: Bloomsbury.

Horowitz M and Leino R (2020) 'Pandemic and Public Service Media: Lessons from Finland'. Baltic Screen Media Review 8(1).

Jupowicz-Ginalska A (2020) 'COVID-19 on the Covers of Socio-Political Magazines as an Example of Media Polarisation'. Baltic Screen Media Review 8(1).

Mikos L (2020) 'Film and Television Production and Consumption in Times of the COVID-19 Pandemic The Case of Germany'. Baltic Screen Media Review 8(1). Noonan C (2020) 'Public funding in a time of crisis: Film funds and the pandemic'. Baltic Screen Media Review 8(1).

Øfsti M (2020) 'Distributor strategies in the face of closed cinemas: Norwegian responses to COVID-19'. Baltic Screen Media Review 8(1).

Raats T (2020) 'The resilience of small television markets to COVID-19: the case of Lockdown'. Baltic Screen Media Review 8(1).

Rohn U (2020) 'Digikultuur. Televisioon platvormide ajastul'. Postimees, 22.05.2020.

Straubhaar JD (1991) 'Beyond media imperialism: Assymetrical interdependence and cultural proximity'. Critical Studies in Mass Communication 8(1): 39-59. Zaezjev A (2020) 'From Dusk till "DAU": the rise of heterotopic cinema in the times of pandemic'. Baltic Screen Media Review 8(1). 